\title{
Mobility during the Upper Palaeolithic in Greece: Some Suggestions for the Argolid Peninsula
}

\section{Paraskevi Elefanti \& Gilbert Marshall}

Hellenic Foundation for Research and Innovation

Department of History and Archaeology, University of Athens

\begin{abstract}
The mobile hunting and gathering way of life has persisted for over $95 \%$ of human history. As ethnographic studies of recent societies have highlighted, mobility was key to the exploitation of the natural environment, while at the same time enabling groups to regulate their populations through fission and fusion. Combinations of mobility, technology and social networks enabled the near complete global spread of hunter-gatherers prior to the more settled farming way of life. Despite difficulties in extrapolating back in time from modern societies, their study can provide useful baseline indicators as to how settlement and subsistence was likely to have been organised during the Palaeolithic. The archaeological record as well as the seasonal variation in the natural environment, suggest that the fundamental challenges faced by groups during the Palaeolithic would have been broadly similar to those of today. Our study is based on three major cave sites in the Peloponnesian Argolid and applies the results of recent ethnographic studies to suggest ways in which the distribution of Upper Palaeolithic sites in the area can be understood. Our aim is threefold, to introduce mobility as the fundamental element of the huntergatherer way of life. To introduce the sites of Klissoura, Kephalari and Franchthi caves and finally, to consider how insights from modern societies can be applied to understand the Palaeolithic record of the Argolid.
\end{abstract}

Keywords: Hunter-Gatherers, Mobility, Demography, Caves, Upper Palaeolithic, Argolid, Greece.

\section{Introduction}

This discussion begins with an introduction to the concept of hunter-gatherer mobility as documented in a number of key ethnographic studies. We then present the Palaeolithic evidence from the Peloponnesian Argolid (Fig. 1) and discuss the distribution of these sites in relation to the ethnographic evidence. The mobile hunter-gatherer way of life has persisted for over $95 \%$ of human history. Although small numbers of groups still exist, they have been marginalised and form mere remnants of a way of life which led to the almost complete human colonisation of the earth by the beginning of the Holocene CONTACT: Paraskevi Elefanti, paraskevielefanti@gmail.com Gilbert Marshall, gilbert.marshall86@gmail.com 
(Cummings et al. 2014). Hunter-gatherers, a concept which gained prominence during the European Enlightenment of the eighteenth century (Barnard 2014), subsisted through combinations of hunting, gathering, fishing and trapping, with little evidence for deliberate modification of the landscape (Daniau et al. 2010). They tend to be organised in small groups and have belief systems focused on kin and the natural world (Winterhalder 2001: 12; Lee \& Daly 2002). But the key element of this way of life is mobility, through which they exploit naturally occurring patches of seasonal plant and animal resources. Once these are depleted and travelling times increase beyond a critical threshold, they move on and the pattern is repeated. Vacated patches rejuvenate as new plants sprout and animal populations recover, while at the same time the residential site is naturally cleansed. The nature of this system is multifaceted and although dietary requirements and travelling time are important determinates of when and how far the group will move; other aspects would also have played a role. For example, the state of the site (Kelly 1995: 147-148), the need to monitor the landscape or to maintain extralocal connections. Although this way of life still persists in pockets, it has been heavily influenced by interaction with farming societies through trade and interaction (Takeuchi 2005) and it is therefore important to be mindful of this when attempting to infer past behaviours on the basis of modern analogies (Kelly 1995: 333-334).

To begin with we present an overview of mobility as the key to settlement and subsistence amongst modern hunter-gatherers and present some of the models developed from ethnographic studies. We then briefly describe the archaeological record of the Argolid Peninsula and in the light of the ethnographic evidence, make some suggestions as to how settlement and subsistence may have been organised in this part of Greece during the Palaeolithic.

\section{Mobility as key to the hunter-gatherer way of life}

Mobility allows hunter-gatherers to effectively exploit the natural environment and to adjust to fluctuations in the spatial and temporal distribution of resources (Kelly 1995: 111; Gamble 2013: 75; Grove 2009). The frequency of residential moves is variable, in some cases up to 60 times per year, as determined by the density of resources in each patch (Kelly 1995: table 4; Winterhalder 2001: 21).

In addition to subsistence, mobility also has demographic and social dimensions, with groups splitting in order to regulate pressure on the environment, to expand geographic range or to defuse tensions. At other times, groups may come together in order to exploit specific abundances or to participate in social gatherings (Kelly 1995: 111; Lee \& Daly 2002: 1-2; Hamilton et al. 2016: 124). In addition to mobility associated with hunting and gathering and patch to patch residential movements, other tasks are often embedded, the collection of raw materials or the monitoring of the social and natural landscape (Binford \& Stone 1985; Binford 1979).

Despite differences in environment, diet and social organisation between hunter-gatherers (Hamilton et al. 2016: 124), mobility is the key which allows naturally occurring resources 
to be effectively exploited. The way in which this is achieved is dependent on the density and seasonality of resources, which are in turn linked to latitudinal primary productivity. In less seasonal mid latitude and high primary productivity environments such as tropical rainforests, resources tend to be widely distributed, at low density and often difficult to access. Animals are small, highly mobile and solitary, while edible plants are often located high in the canopy. Groups are small and move frequently between patches as energy expended quickly exceeds calorific returns. Such environments are homogenous and distances travelled between residential sites are typically short, while this homogeneity also means that there is little reason for the group to revisit a specific location. Hunting and gathering is a daily group activity, often with age and gender differentiation (Kelly 1995: 159). In contrast, in higher and lower latitude more seasonal environments where resources are more dispersed, groups tend to reoccupy specific locations, with hunting and gathering over longer distances and many days, usually by task specific teams. Resources are returned to the residential site which serves as an important repeatedly revisited point in the landscape (Kelly 1995: 117-120).

These two models of moving people to resources versus resources to people were formalised by Binford (1980) as the forager collector continuum. Residentially mobile foragers move as a group and locate close to a patch of resources, moving on once productivity declines and journey times increase beyond a certain threshold. Collectors on the other hand move further and between repeatedly used locations where the majority of the group settles and to which resources are brought back by logistically organised teams. A third proposed system was that of serial specialists (Binford 1980: 17), with groups moving between brief seasonal abundances such as animal migrations or fish runs.

Material evidence for residentially mobile foragers is characterised by minimal reuse of specific locations, resulting in a low density blanket of cultural residues (Foley 1981). Investment in residential sites is minimal since once the patch is exhausted and the group moves on, there is no reason to return. In contrast, logistically mobile collectors invest in residential sites since they are likely to return. Repeated use results in the accumulation of cultural residues, features and the structured use of space. These two opposites of the mobility continuum are useful concepts but should not be used to buttonhole groups (see also Preston \& Kador 2018).

\section{Palaeolithic sites in the Argolid}

Thirty Palaeolithic and Mesolithic sites and findspots have been identified in the Argolid Peninsula. These include four excavated cave sites (but see also Koumouzelis et al. 2004) and twenty-seven findspots of surface collected chipped stone artefacts (Elefanti et al. 2015). These smaller findspots were mostly identified during surface survey by the Berbati-Limnes (Wells \& Runnels 1996), Kandia (Runnels et al. 2005) and Southern Argolid survey projects (Jameson et al. 1994). Although the sample of sites and findspots is small, the area is comparatively rich compared to many others in Greece. 
All sites and findspots are located below 200masl on low hills surrounding larger plains and river valleys (Elefanti \& Marshall 2015). The excavated caves of Kephalari and Klissoura are located on the western and eastern edges of the Argive Plain respectively, while Franchthi Cave lies close to the south-eastern end of the peninsula. The location of Ulbrich Cave which was excavated in the late 1920s by Adalbert Markovits is currently unknown, although it was probably located to the north of the Argive Plain and south of the Nemea Valley (Galanidou 2003: 107-108).

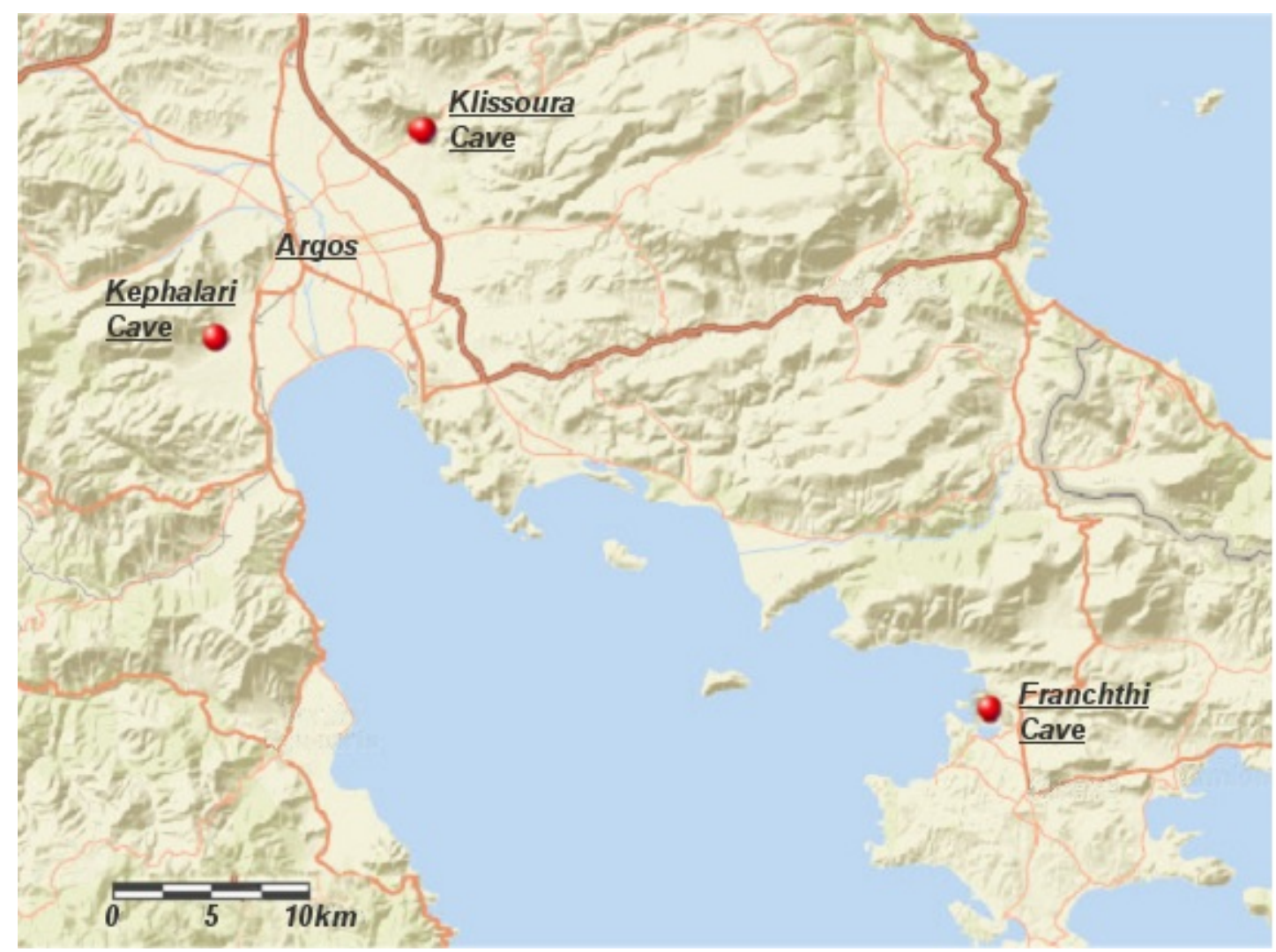

Figure 1. Location of the three major caves mentioned in the text. The position of Ulbricht Cave is unknown, probably to the north of Klissoura.

\section{Kephalari Cave}

Kephalari is a substantial limestone cave at approximately $27 \mathrm{masl}$, situated on the southwestern edge of the Argive Plain (Fig. 2). It is an impressive solution cave and was formed by the springs of the Erasinos River which still flow today from below the mouth. The cave consists of two parallel chambers of approximately $5 \mathrm{~m}$ in height and width and two south facing entrances, one larger than the other. The site has been extensively developed by the Orthodox church of Zoodochos Pigi, particularly the area outside which has been raised and paved. 


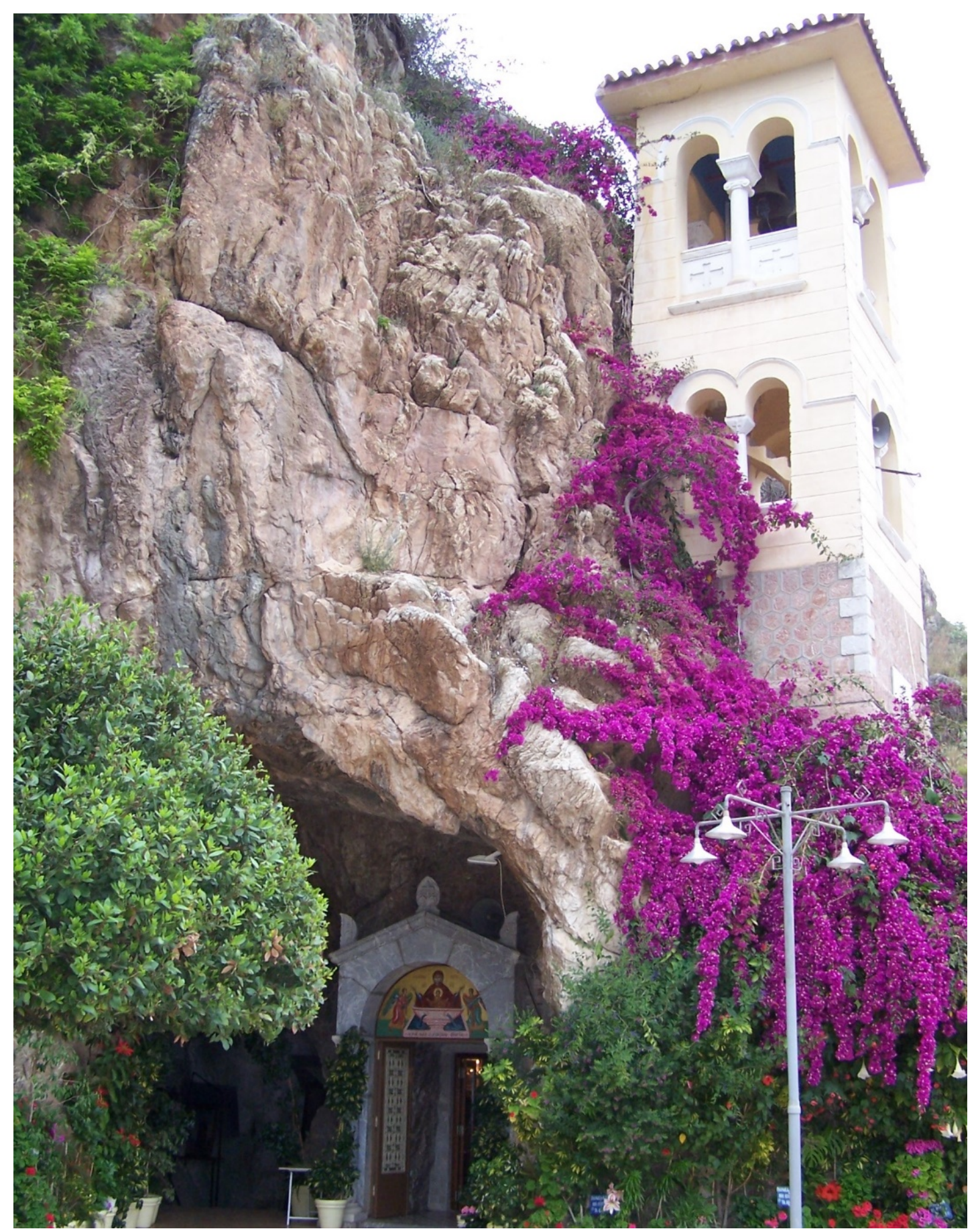

Figure 2. Kephalari Cave showing the smaller right hand entrance and the façade of the church of Zoodochos Pigi.

Excavations were carried out approximately a third of the way into the main chamber in the mid-1970s by Rainer Felsch and then Ludwig Reisch (1976), producing an Upper and Middle Palaeolithic sequence. The Upper Palaeolithic chipped stone assemblages were similar to those from nearby Klissoura Cave, with Aurignacian, Mediterranean Gravettian and Epigravettian facies. Sandwiched between the Middle Palaeolithic and Aurignacian, was a thin horizon of Uluzzian character (Marshall in prep). Preliminary faunal analysis points to hunting of European fallow deer, roe deer, red deer, aurochs, European ass, boar, ibex and chamois. Smaller species were also targeted, ground nesting birds, hare and tortoise, along with small scale fishing (Starkovich \& Ntinou 2017; Starkovich et al. 2018), 
while the tooth eruption evidence points to occupation during all seasons (Starkovich pers com.). Although evidence for the structured use of space was not identified at Kephalari, the excavations produced what appears to be an Upper Palaeolithic burial, possibly associated with incised shell ornaments (Ludwig Reisch unpublished excavation records, Stiner pers com.).

\section{Klissoura Cave}

Klissoura (Fig. 3) is much smaller than Kephalari, more of a rockshelter, although a still buried chamber may be present (Karkanas pers com.). The site is located at 116 masl on the north-eastern edge of the Argive Plain, approximately $15 \mathrm{~km}$ across the plain from Kephalari and on the northern side of the Klissoura Gorge, close to the mouth of the Berbariotis River which flows through the gorge and into the plain (Koumouzelis et al. 1996). Excavations produced a deep and substantial Middle Palaeolithic sequence dated from the penultimate interglacial, overlain by Upper Palaeolithic and then Mesolithic units (Stiner et al. 2010; Kaczanowska et al. 2010). The chipped stone is similar to that from Kephalari, with Mousterian, Uluzzian, Aurignacian, Mediterranean Gravettian and Epigravettian facies. The position of the site would have enabled a number of environmental niches to be exploited, the gorge, river, surrounding hills and the Argive plain to the west, as well as the Berbati Basin to the north-east. The faunal evidence points to hunting of fallow deer and to a lesser extent European ass, red deer, boar and ibex. Small game including hare, tortoise and partridge increased in importance from the Early Upper Palaeolithic onwards, with bone counts exceeding those of fallow deer towards the end of the Epigravettian. Based on tooth eruption evidence, occupation during all seasons is indicated (Starkovich 2017: 64-79). Evidence for structures was present in the form of clay-lined hearths (Karkanas et al. 2004), as well as a small feature with possible organic cover and perforated shell beads (Stiner et al. 2010: 298-301). These structural features, along with the depth of the sequence and the density of cultural and faunal evidence point to Klissoura as an important repeatedly occupied site.

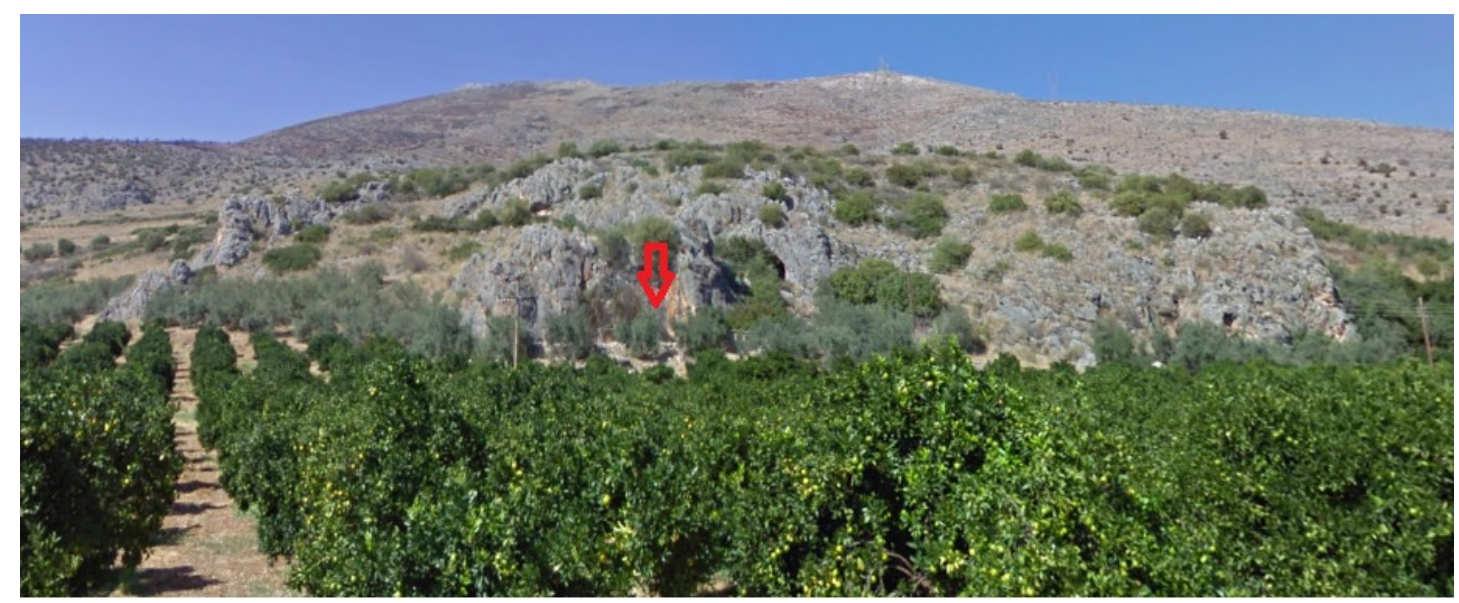

Figure 3. Klissoura Cave from approximately $100 \mathrm{~m}$ away, viewed from the road heading up the gorge to the village of Prosimna. 


\section{Franchtbi Cave}

Franchthi is a limestone cave located close to the end of the Argolid Peninsula. It has a cavernous interior measuring $150 \mathrm{~m}$ by $45 \mathrm{~m}$ and the mouth faces west across the bay of Koilada (Fig. 4). Located at $10 \mathrm{masl}$ and close to the current shoreline, it would have been situated up to $5 \mathrm{~km}$ from the coast during much of the earlier part of the Palaeolithic when sea levels were considerably lower (Van Andel \& Sutton 1987: 40). Facing west, it only receives direct sunlight from mid-day onwards, in contrast to Klissoura and Kephalari which face south and receive the morning sun throughout the year. Although marked by a number of sedimentological breaks (Farrand 2000), like Kephalari and Klissoura it is one of the few sites in Greece in which occupation spanning the Upper (and probably Middle) Palaeolithic to the Neolithic is documented (Perlès 1999; Douka et al. 2011). During the Neolithic, occupation expanded out of the cave with settlement along the shoreline (Jacobsen \& Farrand 1987).

The fauna was dominated by red deer and European ass and to a lesser extent wild boar, auroch and wild goat (Stiner \& Munro 2011: 624). The lack of fallow deer at Franchthi is a notable difference to Kephalari and Klissoura, perhaps related to habitat preference of this species. Smaller animals were again targeted, including hare, hedgehog and ground nesting birds, along with tortoise, turtle and land snails, particularly towards the end of the Upper Palaeolithic when marine resources also gained in importance. As at Kephalari and Klissoura, this may reflect a shift towards less productive but more reliable resources (Stiner et al. 2012: 37-40; Stiner \& Munro 2011: 634), perhaps in response to a decline in larger species, demographic pressure or the loss of coastal lowlands (Starkovich et al. 2018). The appearance of obsidian from the island of Melos also points to more extensive use of coastal and marine environments during the Final Upper Palaeolithic and into the Mesolithic. Trace quantities of obsidian were also recovered at Klissoura and Kephalari (Perlès 1999; Kozlowski \& Kaczanowska 2016; Marshall in prep).

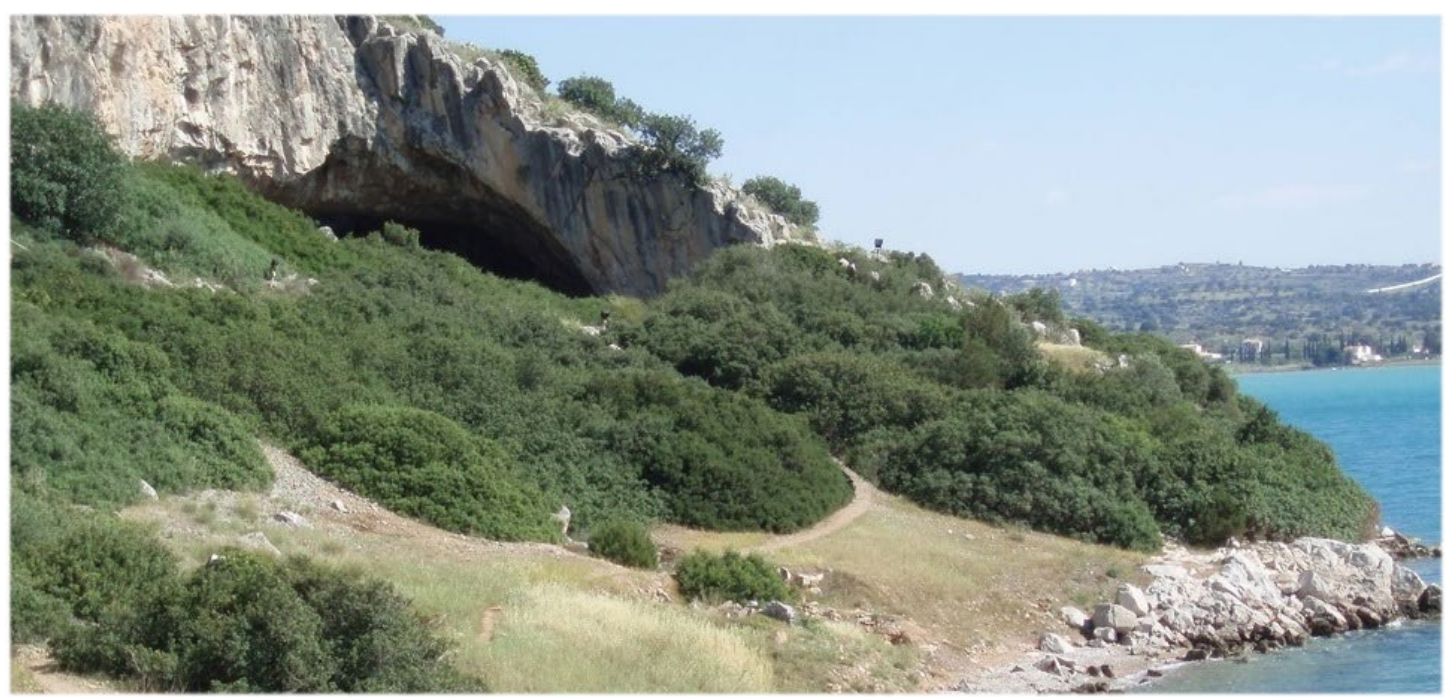


Figure 4. Franchthi Cave showing the main entrance and close proximity of the shoreline. The mouth measures approximately $25 \mathrm{~m}$ across and faces due west.

The evidence points strongly towards continuous and long term use of these three prominent sites during the Palaeolithic and Mesolithic, with similarities in chipped stone and fauna. Despite this, Klissoura appears to have been used more intensively during the earlier part of the sequence while Franchthi flourished towards the end of the Upper Palaeolithic, possibly due to the proximity of the nearby shoreline as sea levels rose. Whether this occupation was sustained in the area during the height of the Last Glacial Maximum (LGM) is unclear as sedimentary units corresponding to this phase appear to be absent at both Klissoura and Franchthi, either due to abandonment or perhaps erosion (Karkanas 2010; Kuhn et al. 2010; Perlès 1999). All three sites were key points at the junction between a range of environments, hills, plains, rivers, coasts and the open sea. Their visibility in the landscape and deep stratigraphic sequences, point to long-lived use during the Palaeolithic and Mesolithic, probably as home bases (Vita Finzi \& Higgs 1970: $6)$.

\section{Mobility during the Palaeolithic}

Based on the location of Kephalari, Klissoura and Franchthi and ethnographic studies of recent hunter-gatherers, our aim is to suggest how settlement and subsistence in the Argolid may have been organised. The variables we will consider include move distance, habitat quality, occupation duration and group size. The starting point for our discussion is the study by Grove (2009), who looked in detail at the ethnographic data assembled by Binford (2001) in his compendium of 339 recent hunter-gatherer societies. Reducing the dataset to 236 residentially mobile groups, these were again divided into those subsisting primarily off hunting (76), gathering (111) and fishing (49). Grove investigated the relationship between move distance and a series of independent variables including habitat quality, average occupation duration and group size. Using stepwise regression, he identified the following relationships between move distance and these variables for each of the three subsistence modes.

Amongst hunters, the average distance moved between residential sites was negatively correlated with habitat quality, but positively with average occupation duration. So in higher quality environments, distances moved between sites tended to be shorter, while longer periods of occupation were correlated with greater distances between sites. This latter relationship was strongest amongst hunters, with animals avoiding areas of human habitation, leading to extended buffer zones. Although less pronounced, this negative relationship between habitat quality and average move distance was also noted amongst gatherers and fishers, while occupation duration had a negligible to non-existent effect on average move distance amongst these groups. Group size showed little consistent relationship with average move distance for all three subsistence modes. Although in theory, larger groups would tend to deplete resources more rapidly, Grove (2009) argued that this effect was mediated by reduced occupation duration rather than longer move 
distances. Larger groups tend to invest in site structure and to carry more gear and include a broader range of members, so restricting distances achievable per move.

\section{Average move distance}

Grove's (2009) regression results using the Binford (2001) dataset can be used to suggest a number of baseline expectations for mobility in the Argolid which can be compared with the distribution of known sites. Although the use of plants is more difficult to quantify, the faunal evidence from the three caves points to the importance of hunting to the diet. Grove's (2009: 8) stepwise regression results for hunters in an environment with mean annual rainfall of around $550 \mathrm{~mm}$, similar to that of the Argolid today (Climatlas 2018), suggest a mean move distance between sites of approximately $17 \mathrm{~km}(\mathrm{~N}=47$, $\mathrm{df}=46, \mathrm{R} 2=0.545, \mathrm{p}<0.0001)$. For groups subsisting predominantly on plant resources, this distance reduces to $12.5 \mathrm{~km}(\mathrm{~N}=40, \mathrm{df}=39, \mathrm{R} 2=0.598, \mathrm{p}<0.0001)$. Bearing in mind the difficulty in estimating rainfall during the Palaeolithic, we have used the modern mean of $550 \mathrm{~mm}$ for the area. The proximity of Kephalari and Klissoura as well as similarities in their dating, fauna and chipped stone assemblages indicates that they were probably being used as part of the same settlement system. The $17 \mathrm{~km}$ between the sites suggested by Grove (2009) and Binford's (1982: 10) complete radius leapfrog pattern, suggests an effective foraging radius around each site of $8.5 \mathrm{~km}$. Kelly (1995: 132-135) cites ethnographic examples in which up to $7 \mathrm{~km}$ represents a critical cut-off for successful hunting and foraging, beyond which returns become uneconomic. The straight line distance between Kephalari and Klissoura is $15 \mathrm{~km}$, so within that predicted for a rainfall mean of $550 \mathrm{~mm}$. Franchthi is located just over $40 \mathrm{~km}$ from both Klissoura and Kephalari, suggesting the presence of intermediate patches and other residential sites. The findspots located during the Kandia survey (Runnells et al. 2005) in the area to the east of the Argolid may represent such locations.

\section{Occupation duration}

Grove (2009: 8) investigated the relationship between occupation duration and average move distance. For a sample of hunting groups, a move distance of $17 \mathrm{~km}$ corresponded to an average occupation duration of 13.5 days $(\mathrm{N}=47, \mathrm{df}=46, \mathrm{R} 2=0.329, \mathrm{p}<0.0001)$ or roughly 24 residential moves per year, with a total annual distance covered of $442 \mathrm{~km}$. With a foraging radius of $8.5 \mathrm{~km}$ equates to a patch size of $227 \mathrm{~km}^{2}$, which for 25 moves results in an annual exploitation area of $5675 \mathrm{~km}^{2}$. There is little in the ethnographic record about how regularly patches are reused, which would be dependent on plant and animal replenishment rates as well as the condition of the site. Short breaks in occupation cannot be identified in the archaeological record, while tooth eruption evidence from Kephalari and Klissoura point to occupation during all seasons (Starkovich pers com.).

\section{Group size}

Group size amongst hunter-gatherers is heavily dependent on resource availability and habitat type (French 2015) and is highest in temperate and tropical coastal environments and lowest in semi-deserts and the Arctic. Lower population densities are found 
amongst groups primarily dependent on terrestrial animals, while highest amongst those exploiting aquatic resources (Binford 2001: 380-383). Groups of between 20 to 30 individuals have been proposed (Kelly 1995: 213, 214; Hill et al. 2011; French 2015). Comparable numbers have also been suggested by Tallavaara et al. (2015: fig 2) for Palaeolithic Europe, based on climate envelope models, Binford's (2001) compendium of hunter-gatherers and dated archaeological sites. For the Peloponnese their simulated group size estimates ranged from 8 to 20 individuals per $100 \mathrm{~km}^{2}$. These estimates relate to the size of subsistence groups rather than the larger numbers necessary for a viable population (see Kelly 1995: 213-214; Gamble 2013: 72). Groups of 20 or more are consistent with the physical size of all three sites in our sample. The area outside of Kephalari measures $20 \mathrm{~m}$ by $6 \mathrm{~m}$ and the main chamber is around $5 \mathrm{~m}$ wide. Klissoura is significantly smaller, although the area in front of the overhang measures $20 \mathrm{~m}$ by $6 \mathrm{~m}$, so similar to Kephalari. The inner chamber at Franchthi is much larger (150 m by $55 \mathrm{~m})$, while the area in front of the mouth is comparable to the two other sites, at around $25 \mathrm{~m}$ by $8 \mathrm{~m}$.

\section{Discussion}

Despite the relatively small sample of three (and possible four) residential caves and 27 smaller findspots, the Argolid is comparatively rich in Palaeolithic and Mesolithic evidence compared to many other parts of Greece. Field survey in the Kandia region to the east of the Argolid has shown that apparent site densities are strongly correlated with visibility and survey effort. This is particularly the case with caves and rockshelters, which are obvious in the landscape and tend to be better preserved. Whether open-air locations were in use as residential sites to the same extent is unknown. The three caves in our sample were occupied during the final Pleistocene and early Holocene and provide the starting point for an investigation of hunter-gatherer settlement and mobility in the Argolid. Growth in the number of sites elsewhere in the Peloponnese offers similar potential for modelling, for example in the Mani Peninsula (Tourloukis \& Harvati 2018). Mindful that our sample is both partial and biased, the aim of our study has been to take a speculative look at the distribution of sites in the Argolid in the light of ethnographic evidence from recent hunter-gatherer societies.

Regression analysis by Grove (2009) suggested residential moves of around $17 \mathrm{~km}$ for groups subsisting primarily from hunting and in rainfall conditions similar to those encountered in the Argolid today. This equates to a foraging radius of $8.5 \mathrm{~km}$, while six to eight kilometres is typical for recent hunter-gatherers who range out on a daily basis. The distance between Kephalari and Klissoura is $15 \mathrm{~km}$, broadly consistent with the ethnographic evidence for residential site spacing. It may be that other cave and open-air residential sites were present around and within the Argive plain. On the other hand and on the basis of the ethnographic evidence, it may be possible that the plain was exploited from Kephalari and Klissoura alone.

Foraging radii of $8.5 \mathrm{~km}$ around these two sites overlap slightly in the middle of the plain and cover most of the rest of its surface. The plain currently extends to $145 \mathrm{~km}^{2}$, 
significantly less than the total area of $454 \mathrm{~km}^{2}$ for the proposed foraging patches of both sites. Reduced sea levels (c. $-120 \mathrm{~m}$ ) during the LGM would have added around $115 \mathrm{~km}^{2}$ to the plain, resulting in a potential total exploitable area of $260 \mathrm{~km}^{2}$, still significantly less than the combined foraging area for the two patches. Although further survey is needed, ethnographic parallels indicate that it is possible for an area the size of the Argive Plain to have been exploited by hunter-gathers operating from just two strategically placed residential sites. The rest of the Argolid is mountainous, with small enclosed basins at elevations from $150 \mathrm{~m}$ to $650 \mathrm{~m}$ and the remnants of a wider lowland coastal strip along the southern edge of the peninsula. Lower sea levels during the LGM would have exposed a corridor of up to $5 \mathrm{~km}$ in width along this coastline, potentially linking the Argive Plain with the area around Franchthi Cave.

Regression analysis based on recent hunter-gatherers and a rainfall regime similar to the Argolid today, suggested occupation durations of two weeks for residential sites, equating to 24 moves per year. Moving to a new patch allowed the previous one to recover and the time needed for such a process would depend on the season, the types of plants and animals and the intensity of previous exploitation. This rate of recovery has implications for the number of patches necessary to sustain the system. Two sites would allow a fortnight recovery window, four sites a month and a half and so on. Considering the size of the Argolid Peninsula and the distribution of patches suitable for hunting and gathering, we suggest a system of eight foraging radii, three centred on our sample sites. Eight patches, each visited three times a year during a total of 24 residential moves, equates to a seven week recovery period and a total annual distance covered of $390 \mathrm{~km}$. Each residential site would be occupied for a total of six weeks per year. But this system is based on the presence of just a single group. Multiple groups would be significantly complicate the picture, requiring many more residential sites, longer occupation durations and reduced patch recovery times.

Residential movement over distances of less than $17.5 \mathrm{~km}$ could be achieved in a day, while foraging over distances of up to $8 \mathrm{~km}$ is also easily achievable. The limited scale of both residential and subsistence mobility is reflected in the chipped stone assemblages at both Kephalari and Klissoura, with local radiolarite and chert the predominant raw materials. Obsidian from Melos is present at very low density at Kephalari and Klissoura during the Final Upper Palaeolithic and Mesolithic (Marshall in prep; Kaczanowska et al. 2010), although more common at Franchthi (Perlès 1999). It provides direct evidence for greater use of inshore waters and corresponds at Franchthi with increased evidence for fishing. During the Upper Palaeolithic there was also a shift towards smaller animals at all three sites and this together with seafaring and fishing may represent a diversification in the diet, possibly in response to the loss of habitat as sea levels rose during the postglacial period.

As to the question where the Palaeolithic and Mesolithic hunter-gatherers of the Argolid would fall in terms of Binford's (1980) residential-logistical continuum, the evidence points to the former, with a forager based strategy in which people were moved to patches 
of resources. But rather than an undifferentiated landscape with high spatial redundancy, the evidence suggests that caves and rockshelters were repeatedly occupied. All three of our sites are located at the junction between a range of environmental niches and close to sources of water. But as caves and shelters are fixed and therefore we would describe the hunter-gatherers of the Argolid as tethered foragers. The unknown in this is the contribution of open-air sites. Those that have been located during surface survey in the area appear to be ephemeral or consist of stray finds, although the presence of large openair sites cannot be ruled out.

\section{Conclusions}

Mobility is a key attribute of the hunter-gather way of life, allowing groups to adapt to changes in the natural environment. Despite the effort expended in surface survey since the 1970s, we have only a partial picture of the distribution of these sites, while incorporating them within regional scale settlement and subsistence systems is far more difficult (Elefanti \& Marshall 2015). The dating evidence is not fine enough, seasonality indicators are too general and lithic raw material collection appears to have been essentially local and only in rare instances helpful in documenting movement. Despite these difficulties and the partial nature of the dataset, the larger sites and smaller findspots from the Argolid provide us with the beginnings of a framework for interpreting the huntergatherer landscape. New targeted field survey may help to expand and refine the picture still further. Based on our initial and admittedly speculative look at the archaeology of the region, we suggest a system of tethered foragers in which groups of around twenty people were moving between prominent repeatedly occupied locations, placing themselves within daily foraging distance to a range of resources. We speculatively suggest that they remained at these residential locations for a fortnight, hunting and gathering in a patch with of radius of $8 \mathrm{~km}$. We suggest a total of around eight such patches and residential centres, with sites visited three times per year and each patch left to recover for around three and a half months. This general pattern was extremely long-lived and persisted from at least the penultimate interglacial until the late Pleistocene. During the Upper Palaeolithic and postglacial period, there appears to have been a shift in strategy, with more extensive hunting, trapping and fishing of smaller animals. Although less productive, these were more reliable than larger species where hunting failure was a significant risk. This shift may have also led to changes in landscape and site use, perhaps with longer periods of occupation and greater investment in site structure, as at Maroulas on Kythnos (Kozlowski \& Kaczanowska 2016).

It is clear that many more sites and findspots remain to be discovered within the Argolid as well as elsewhere in the Peloponnese, the Mani Peninsula to the south and the Elis region in the north west. It is also likely that many sites were lost as sea levels rose after the LGM and our models need to take account of this. Further work is also needed in the northern half of the Argolid, while the apparent lack of larger open-air sites also needs to be addressed, particularly in those areas where caves are absent. 


\section{Acknowledgments}

We are grateful to the Ex Novo editors as well as to the anonymous reviewer for helpful and constructive comments on earlier drafts. Thanks also to Mary Stiner and Britt Starkovich for sharing their thoughts on unpublished data. Errors, omissions and misrepresentations are all our own.

\section{References}

BARNARD, A., 2014. Defining hunter-gatherers: Enlightenment, romantic, and social evolutionary perspectives, in: V. Cummings, P. JORDAN \& M. ZvelEBIL (eds.), The Oxford Handbook of the Archaeology and Anthropology of Hunter-Gatherers. Oxford: Oxford University Press, 43-54.

BINFORD, L., 1979. Organization and formation processes: Looking at curated technologies. Journal of Anthropological Research 35: 255-273.

BINFORD, L., 1980. Willow smoke and dogs' tails: Hunter-gatherer settlement systems and archaeological site formation. American Antiquity 45 (1): 4-20.

BINFORD, L., 1982. The Archaeology of place. Journal of Anthropological Archaeology 45: 420.

BINFORD, L., 2001. Constructing Frames of Reference. Berkeley (CA): University of California Press.

Binford, L., \& N. STONE, 1985. "Righteous rocks" and Richard Gould: Some observations on a misguided "debate". American Antiquity 50: 151-153.

CLIMATLAS, 2018. http:/ / climatlas.hnms.gr Accessed 04 December 2018.

Cummings, V., P. Jordan \& M. Zvelebil (eds.), 2014. The Oxford Handbook of the Archaeology and Anthropology of Hunter-Gatherers. Oxford: Oxford University Press.

Daniau, A-L., F. D'Errico \& M. SANCHEZ-GOnI, 2010. Testing the hypothesis of fire use for Ecosystem Management by Neanderthal and Upper Palaeolithic Modern Human populations. PLOS ONE 5(2): e9157. doi:10.1371/journal.pone.0009157

Douka, K., C. Perlès, H. Valladas, M. Vanhaeren \& R. Hedges, 2011. Franchthi Cave revisited: The Age of the Aurignacian in south-eastern Europe. Antiquity 85: 11311150.

Elefanti, P., \& G. MARshald, 2015. Late Pleistocene hominin adaptations in Greece, in: F. Coward, R. Hosfield, M. Pope, \& F. Wenban-Smith (eds.), Settlement, society and Cognition in Human Evolution. Cambridge: University Press, Cambridge, 198-213.

Elefanti, P., Marshald, G. \& C. Gamble, 2015. Prehistoric Stones of Greece: A resource from field-survey. http://archaeologydataservice.ac.uk/archives/view/stones_ahrb_2013/ Accessed 03 December 2018

Farrand, W., 2000. Depositional History of Franchthi Cave: Stratigraphy, sedimentology, and chronology. Excavations at Franchthi Cave, Greece, Fascicle 12. Bloomington: Indiana University Press.

FOLEY, R., 1981. Off-site archaeology: an alternative approach for the short-sited, in: I. Hodder, G. Isaac \& N. Hammond (eds.), Pattern of the past. Studies in honour of David Clarke. Cambridge: Cambridge University Press, 157-182.

FrenCH, J., 2015. Demography and the Palaeolithic archaeological record. Journal of Archaeological Method and Theory 23. DOI: 10.1007/s10816-014-9237-4.

GALANIDOU, N., 2003. Reassessing the Greek Mesolithic: the pertinence of the Markovits collections, in: N. Galanidou \& C. Perlès (eds.), The Greek. Mesolithic. Problems and perspectives. British School at Athens, Studies 10: 99-112.

Gamble, C., 2013. Settling the Earth. The Archaeology of Deep Human History. Cambridge: Cambridge University Press. 
Grove, M., 2009. Hunter-gatherer movement patterns: causes and constraints. Journal of Anthropological Archaeology 28: 222-233.

Hamilton, M., H. Lobo, E. Rupley, H. Youn \& G. West, 2016. The ecological and evolutionary energetics of hunter-gatherer residential mobility. Evolutionary Anthropology 25: 124-132.

Hill, K., R. Walker, M. Bozicevic, J. Eder, T. Headland, B. Hewlett, A. Magdalena Hurtado, F. Marlowe, P. Wiessner \& B. Wood, 2011. Co-residence patterns in hunter-gatherer societies show unique human social structure. Science 331: 1286-1289.

Jacobsen, T., \& W. Farrand, 1987. Franchthi Cave and Paralia. Maps, plans, and sections. Excavations at Franchthi Cave, Greece. Fascicle 1. Bloomington: Indiana University Press.

Jameson, M., C. Runnels \& TJ. VAn Andel (eds.), 1994. A Greek Countryside. The Southern Argolid from Prehistory to the Present Day. Stanford: Stanford University Press, 214-258.

KaCZAnowska, M., J. KozŁowski \& K. SOBCZYK, 2010. Upper Palaeolithic human occupations and material culture at Klissoura Cave 1. Eurasian Prehistory, 7.2: 133-285.

Karkanas, P., M. Koumouzelis, J. Kozłowski, V. Sitlivy, K. SobCzyK, F. Berna \& S. WIENER, 2004. The earliest evidence for clay hearths: Aurignacian features in Klissoura Cave 1, southern Greece. Antiquity 78: 513-525.

KARKANAS, P., 2010. Geology, stratigraphy, and site formation processes of the Upper Palaeolithic and later sequence at Klissoura Cave 1. Eurasian Prehistory, 7.2: 15-36.

KELLY, R., 1995. The Foraging Spectrum. Diversity in Hunter-Gatherer Lifeways. Washington and London: Smithsonian Institution Press.

Koumouzelis, M., J. Kozłowski, M. Nowak, K. SobczyK, M. Kaczanowska, M. PAWlikowsKi, \& A. PAZDur, 1996. Prehistoric settlement in the Klissoura Gorge, Argolid, Greece (Excavations 1993, 1994). Prehistoric Eurasia 8: 143-173.

Koumouzelis M., J. Kozłowski, M. KaczanowsKa, 2004. End of the Palaeolithic in the Argolid (Greece): Excavation in Cave 4 and Cave 7 in the Klissoura Gorge. Eurasian Prehistory 2.2: 33-56.

KOZLOWSKI, J., \& M. KACZANOWSKA, 2016. The role of lithics in understanding the Mesolithic to Neolithic transition in Greece, in: P. Elefanti, N. Andreasen, P.N. Kardulias \& G. Marshall (eds.) Lithics Past and Present. Perspectives on Chipped Stone Studies in Greece. Studies in Mediterranean Archaeology, CXLIV, Uppsala: Paul Åströms Förlag, 47-67.

Kuhn, S., J. Pigati, P. Karkanas, M. Koumouzelis, J. Kozłowski, M. Ntinou \& M. STINER, 2010. Radiocarbon dating results for the Early Upper Palaeolithic of Klissoura Cave 1. Eurasian Prehistory, 7.2: 37-46.

LEE, R., \& R. DAly (eds.), 2002. The Cambridge Encyclopaedia of Hunters and Gatherers. Cambridge: Cambridge University Press.

PERLÈs, C., 1999. Long-term perspectives on the occupation of the Franchthi Cave: continuity and discontinuity, in: G.N. BaIley, E. Adam, E. Panagopoulou, C. Perlès \& K. ZaCHOS (eds.), The Palaeolithic Archaeology of Greece and Adjacent Areas. Proceedings of the ICOPAG Conference, Ioannina, September 1994. British School at Athens Studies 3: 311-318. Preston, P., \& T. KADOR, 2018. Approaches to Interpreting Mesolithic Mobility and Settlement in Britain and Ireland. Journal of World Prehistory 31(3): 321-345. https://doi.org/10.1007/s10963-018-9118-y.

REISCH, L., 1976. Beobachtungen an Vogelknochen aus der Spätplaistozän der Hohle von Kephalari. Archäologische Korrespondenzblatt 6: 261-265.

Runnels, C., E. Panagopoulou, P. Murray, G. Tsartsidou, S. Allen, K. Mullen, $\&$ E. TOURLOUKIS, 2005. A Mesolithic landscape in Greece: Testing a site-location model in the Argolid at Kandia. Journal of Mediterranean Archaeology 18.2: 259-285. 
Starkovich, B., 2017. Paleolithic subsistence strategies and changes in site use at Klissoura Cave 1 (Peloponnese, Greece). Journal of Human Evolution 111: 63-84.

StARKOVICH, B., \& M. NTINOU, 2017. Climate change, human population growth, or both? Upper Paleolithic subsistence shifts in southern Greece. Quaternary International 428: $17-32$.

Starkovich, B., N. Munro \& M. Stiner, 2018. Terminal Pleistocene subsistence strategies and aquatic resource use in southern Greece. Quaternary International 465: 162176.

Stiner, M., J. KoZłowski, S. KuHn, P. KARKAnAS \& M. KoumouZelis, 2010. Klissoura Cave 1 and the Upper Palaeolithic of southern Greece in cultural and ecological context. Eurasian Prehistory 7.2: 309-321.

STINER, M., \& N. MunRo, 2011. On the evolution of diet and landscape during the Upper Paleolithic through Mesolithic at Franchthi Cave (Peloponnese, Greece). Journal of Human Evolution 60: 618-638.

Stiner, M., N. MunRo \& B. STARKOVICH, 2012. Material input rates and dietary breadth during the Upper Paleolithic through Mesolithic at Franchthi and Klissoura 1 Caves (Peloponnese, Greece). Quaternary International 275: 30-42.

Tallavaara, M., M. LuOtob, N. Korhonenc, H. Järvinend \& H. SeppäD, 2015. Human population dynamics in Europe over the Last Glacial Maximum. Proceedings of the National Academy of Sciences 112.27: 8232-8237.

TAKEUCHI, K., 2005. The Ambivalent symbiosis between the Aka hunter-gatherers and neighboring farmers, in K. TAKEUCHI (ed.) Culture Conservation and Development in African Rain Forest (Research report of MEXT Grant-in-Aid for Scientific Research), 11-28.

Tourloukis, V., \& K. Harvati, 2018. The Palaeolithic record of Greece: A synthesis of the evidence and a research agenda for the future. Quaternary International 466A: 48-65.

VitA-FinZI, C., \& E. Higgs, 1970. Prehistoric economy in the Mount Carmel area of Palestine: site catchment analysis. Proceedings of the Prehistoric Society 36: 1-36.

VAn Andel, TJ., \& S. SutTOn, 1987. Landscape and People of the Franchthi Region. Excavations at Franchthi Cave, Greece, Fascicle 2. Bloomington: Indiana University Press.

Wells, B. \& C. RunNels (eds.), 1996. The Berbati-Limnes archaeological survey 19881990. Acta Instituti Atheniensis Regni Sueciae, Series 4.XLIV, Stockholm: Paul Åströms Förlag, 9-22.

WinTERHALDER, B., 2001. The behavioural ecology of hunter-gatherers, in: C. PANTERBRICK, R. H. LAYTON \& P. ROWLEY-CONWY (eds.), Hunter-Gatherers: An interdisciplinary Perspective, Cambridge: Cambridge University Press, 12-35. 
22 PARASKEVI ElEFANTI \& GILBERT MARSHALL 